\title{
Hepatic Adenomatosis: Diagnosis and Management Dilemma
}

\author{
Norly S and Razman J
}

Department of Surgery, Division of Hepatobiliary, Universiti Kebangsaan Malaysia Medical Centre, Jalan Yaacob Latiff, 56000 Cheras, Kuala Lumpur

\begin{abstract}
:
Hepatic adenomatosis is a rare, benign tumour of the liver. It was first described by Flejou et al as multiple adenomas in an otherwise normal liver parenchyma. Although benign, it can present as a diagnostic challenge because the lesions can be difficult to distinguish from other hepatic tumours. Patients can be asymptomatic and the diagnosis may only be made incidentally. We describe the case of 40-year-old Malay lady who was incidentally found to have hepatomegaly. Radiological examinations revealed a complex left ovarian cyst with multiple liver lesions. Biopsy of the liver lesion showed features of hepatic adenomatosis. Literature review was done and the dilemma in managing her was discussed.
\end{abstract}

\section{KEYWORDS: Hepatomegaly, hepatic adenomatosis, hepatocellular carcinoma}

\section{INTRODUCTION}

Hepatic adenoma is a rare, benign tumour of the liver. It occurs mostly in women of reproductive age who are taking oral contraceptives. ${ }^{1,2}$ It is also more commonly seen in patients with glycogen storage disease, diabetes mellitus, and male patients taking anabolic steroid. The lesion is typically solitary in up to $80 \%$ of cases, but occasionally 2-3 nodules may be present.

Hepatic adenomatosis, first recognized by Flejou et al, ${ }^{1}$ is characterized by multiple adenomas arising in an otherwise normal liver parenchyma. Although it has the same histologic features with hepatic adeno$\mathrm{ma}$, it is considered a distinct entity. Unlike hepatic adenoma, hepatic adenomatosis has neither female predominance nor relation to oestrogen or progesterone intake.

Even though hepatic adenomatosis is a benign disease, it can present as a diagnostic challenge because the lesions can be difficult to distinguish from other hepatic tumours. The natural history is also not clearly defined due to its rarity. The disease may be complicated by spontaneous rupture of the tumour, particularly those greater than $5 \mathrm{~cm}$ in size. ${ }^{3}$ The overall rate of bleeding can be as high as $62.5 \% .^{1,3}$ Malignant transformation to hepatocellular carcinoma (HCC)

Corresponding author

Dr. Norly Salleh, Registrar, Department of Surgery,

Division of Hepatobiliary,

Universiti Kebangsaan Malaysia Medical Centre, email: norlysalleh@hotmail.com can also occur in less than $10 \%$ of cases. ${ }^{4}$

As there are no data on the optimal management of hepatic adenomatosis, treatment options are dictated by the likelihood of the development of complications. In the current case study we will highlight the difficulty in diagnosing the disease and the dilemma in managing this patient.

\section{CASE REPORT}

A 40-year-old healthy Malay lady was seen in the Gynaecology Clinic for primary infertility. She was diagnosed to have endometriosis and subcutaneous depot injection of Leuprolide actetate was started. During examination, the gynaecologist incidentally found a hepatomegaly. Abdominal ultrasonographic and CT scan examinations revealed a complex left ovarian cyst measuring $3.7 \times 4.8 \times 4.2 \mathrm{~cm}$. There were also numerous hypodense hepatic lesions involving both lobes (Figures $1 \mathrm{a}$ and $1 \mathrm{~b}$ ). Her tumour marker, CA 125, was within normal range.

She was diagnosed to have an ovarian carcinoma with multiple liver metastases and was planned for laparotomy, total abdominal hysterectomy with bilateral salpingo-oophorectomy. Unfortunately she default the treatment and showed up more than six months later with progressive abdominal distension and significant weight lost.

Laboratory tests revealed bilirubin of $6 \mathrm{umol} / \mathrm{L}$, while alkaline transaminase and alkaline phosphatase were elevated at $62 \mathrm{U} / \mathrm{L}$ (normal 0-40) and $608 \mathrm{U} / \mathrm{L}$ (normal 35-110), respectively. Gamma-Glutamyl Transferase was also raised at $461 \mathrm{U} / \mathrm{L}$ (normal 7-32). Her tumour markers were AFP: $11.23 \mathrm{ng} / \mathrm{ml}$ (normal 0-6.72), CEA: $5.9 \mathrm{ng} / \mathrm{ml}$ (normal 0-3), CA 125: $37 \mathrm{U} / \mathrm{ml}$ (normal 0-35), CA 19.9: $57 \mathrm{U} / \mathrm{ml}$ (normal <37). Repeat CT scan 
of her abdomen showed a grossly enlarged liver. Hypodense lesions in the liver were slightly more compared to previously (Figures $2 \mathrm{a}$ and $2 \mathrm{~b}$ ). There was no change in size of the left complex ovarian cyst.

An ultrasonographic-guided biopsy of one of the liver lesion showed liver tissue comprising of normal liver parenchymal and tumour fragments. The tumour was composed of well-differentiated hepatocytes with abundant eosinophilic granular cytoplasm. There was no portal tracts identified within the tumour. These findings were consistent with hepatic adenomatosis, but a well-differentiated HCC was unable to be ruled out.

A gadolinium-enhanced MRI was ordered and it showed liver lesions most likely to be adenomatosis. But there were also the presence of 2 foci of increased lesional liver tracer uptake which could suggest a malignant transformation.

\section{DISCUSSION}

Hepatic adenomatosis is very rare and notoriously difficult to diagnose. Due to management difference, it has to be differentiated from other diseases causing multiple liver lesions including metastatic disease, multifocal HCC and focal nodular hyperplasia (FNH). Clinically patient may be asymptomatic, or they may present with non-specific symptoms. Abnormal liver enzyme levels may be observed. Distinguishing hepatic adenomatosis from FNH or HCC based on laboratory findings is usually not possible because these conditions may also give similar results. Patients with HCC usually have highly elevated AFP, but not all patient do, making differentiation more difficult. ${ }^{5}$ Also, there may be coexistence of adenomatosis and carcinoma in the same liver, which is probably what our patient has. Liver biopsy which we did might not be representative and might be misleading. Furthermore, for this patient, we were still unable to ascertain whether the complex ovarian cyst that she has is of a benign or a malignant entity.

Radiological appearance of hepatic adenomatosis can be variable depending of the extent of intra-tumoural fat, necrosis, and haemorrhage. On CT scan and MRI they show homogenous enhancement in the hepatic arterial phase, which may also be seen on FNH and HCC. ${ }^{6,7}$ Most hepatic adenomatosis have intense enhancement during the early arterial phase and are isointense to liver tissue on delayed imaging on gadolinium-enhanced MRI. This is a relatively common feature of fat-containing adenomatosis. But, a small number of HCC do contain fatty tissues and may mimic hepatic adenomatosis.

The management of hepatic adenomatosis is challenging because of the low but grave risk of haemorrhage or malignant transformation. Because of these risks, complete surgical resection is the treatment of choice for all patients who can tolerate surgery. However, it is often not possible due to the multiplicity of the lesions. Our patient has extensive disease and surgical resection is not feasible. There is also the probability of a coexisting HCC and ovarian malignancy.

As a summary we present a case of a lady with an incidental finding of hepatomegaly. Radiological and histopathological examination suggests that she could have hepatic adenomatosis. However clinically she was cachexic and could be having a malignant condition, either primarily from the liver or a metastasis from the ovary. Regardless of her diagnosis, we have opted to treat this patient conservatively. But should she later present with one of the complications, our dilemma in managing her will continue.

\section{REFERENCES}

1. Flejou JF, Barge J, Menu Y, et al. Liver adenomatosis: an entity distinct from liver adenoma? Gastroenterology 1985; 89:1132-8

2. Perret AG, Mosnier JF, Porcheron J, et al. Role of oral contraceptives in the growth of a multilobular adenoma associated with a hepatocellular carcinoma in a young woman. J Hepatol 1996; 25:976-9

3. Ribeiro A, Burgart LJ, Nagorney DM, Gores GJ. Management of liver adenomatosis: results with a conservative surgical approach. Liver Transpl Surg 1998; 4:388-98

4. Foster JH, Berman MM. The malignant transformation of liver cell adenomas. Arch Surg 1994; 129:712-7

5. Ault GT, Wren SM, Ralls PW, Reynolds TB, Stain SC. Selective management of hepatic adenomas. Am Surg 1996; 62(10):825-9

6. Chiche L, Thong D, Salame E, et al. Liver adenomatosis: reappraisal, diagnosis, and surgical management. Ann Surg 2000; 23:74-81

7. Ichikawa T, Federle MP, Grazioli L, Nalesnik M. Hepatocellular adenoma: multiphasic CT and histopathologic findings in 25 patients. Radiology 2000; 214(3):861-8 
Figure 1a and $1 \mathbf{b}$. Computed tomography scan demonstrating multiple hypoechoic lesions in both lobes of the liver.

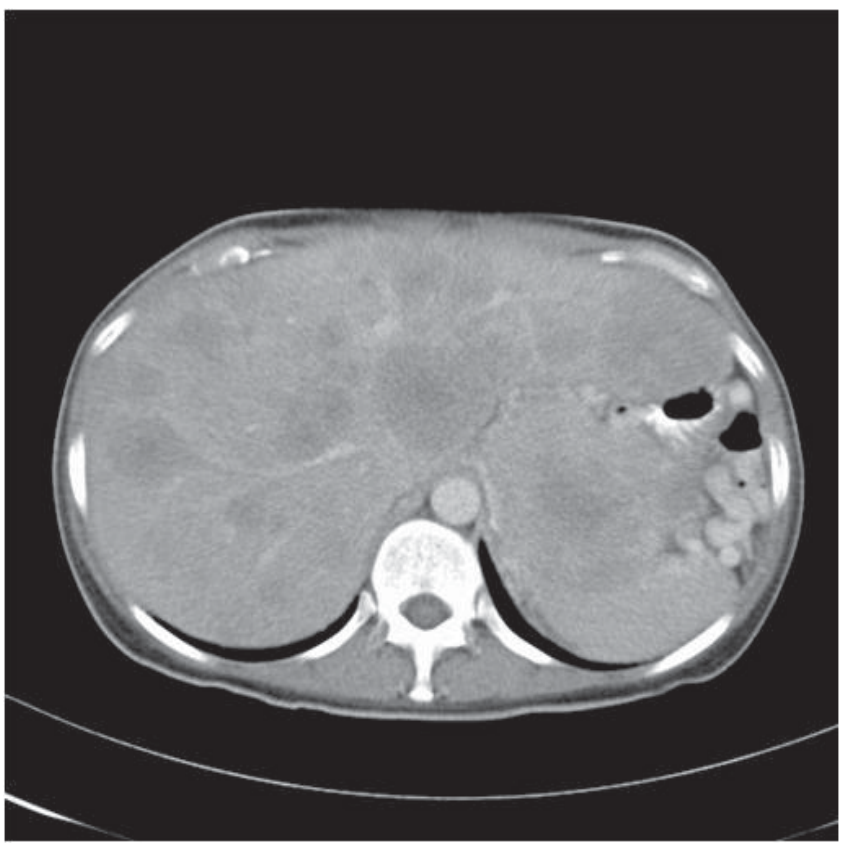

(a)

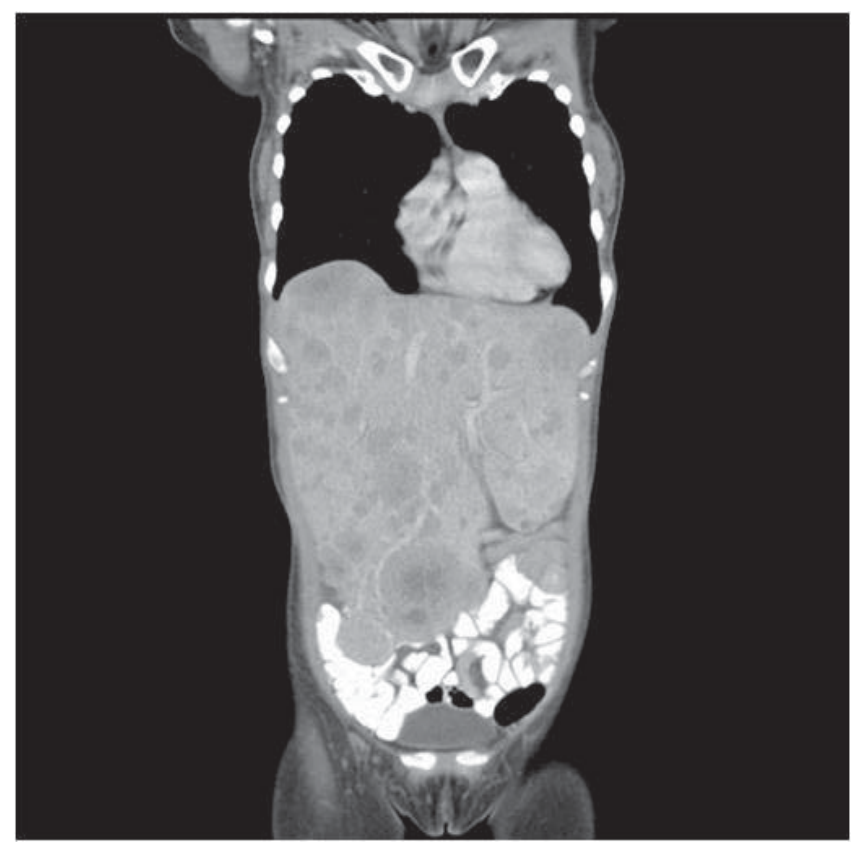

(b)

Figure $\mathbf{2 a}$ and $\mathbf{2 b}$. Computed tomography scan of the patient done 6 months later showing almost similar findings to the previous scan.

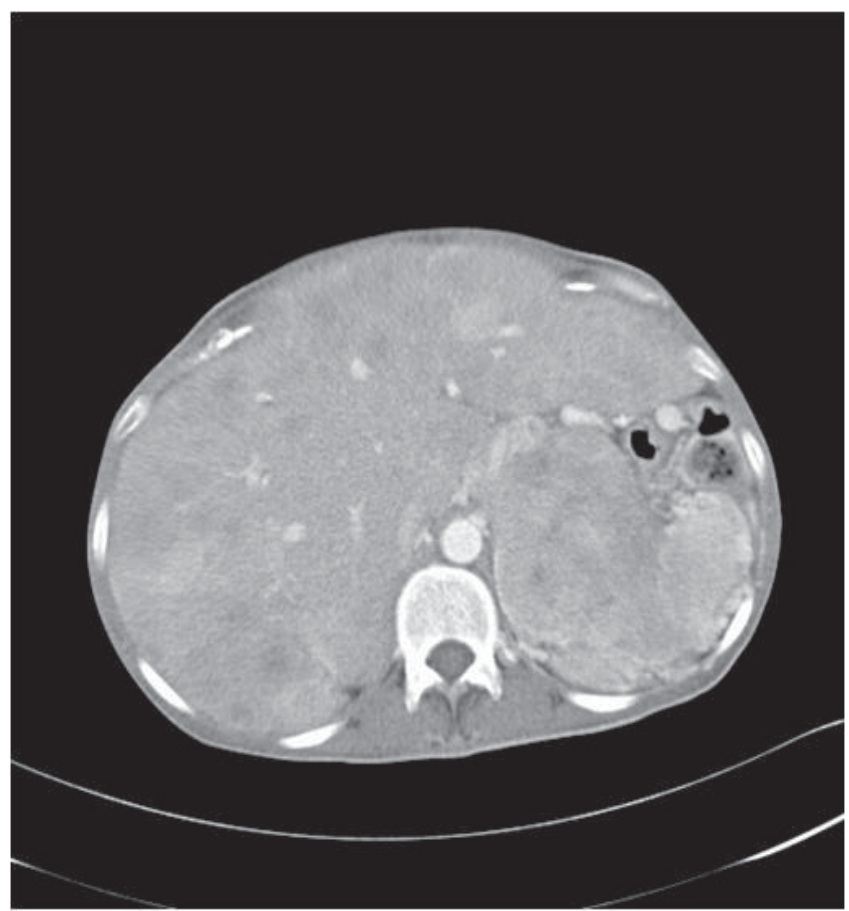

(a)

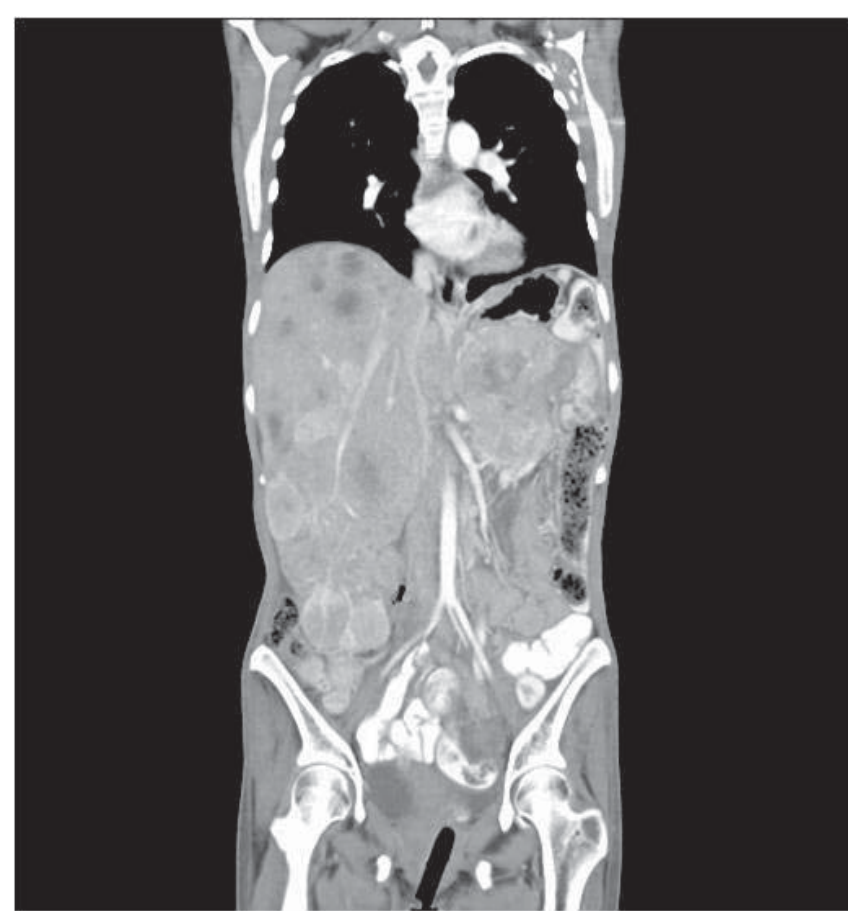

(b) 
THE InTERnAtional MedicAl JOURnal Malaysia

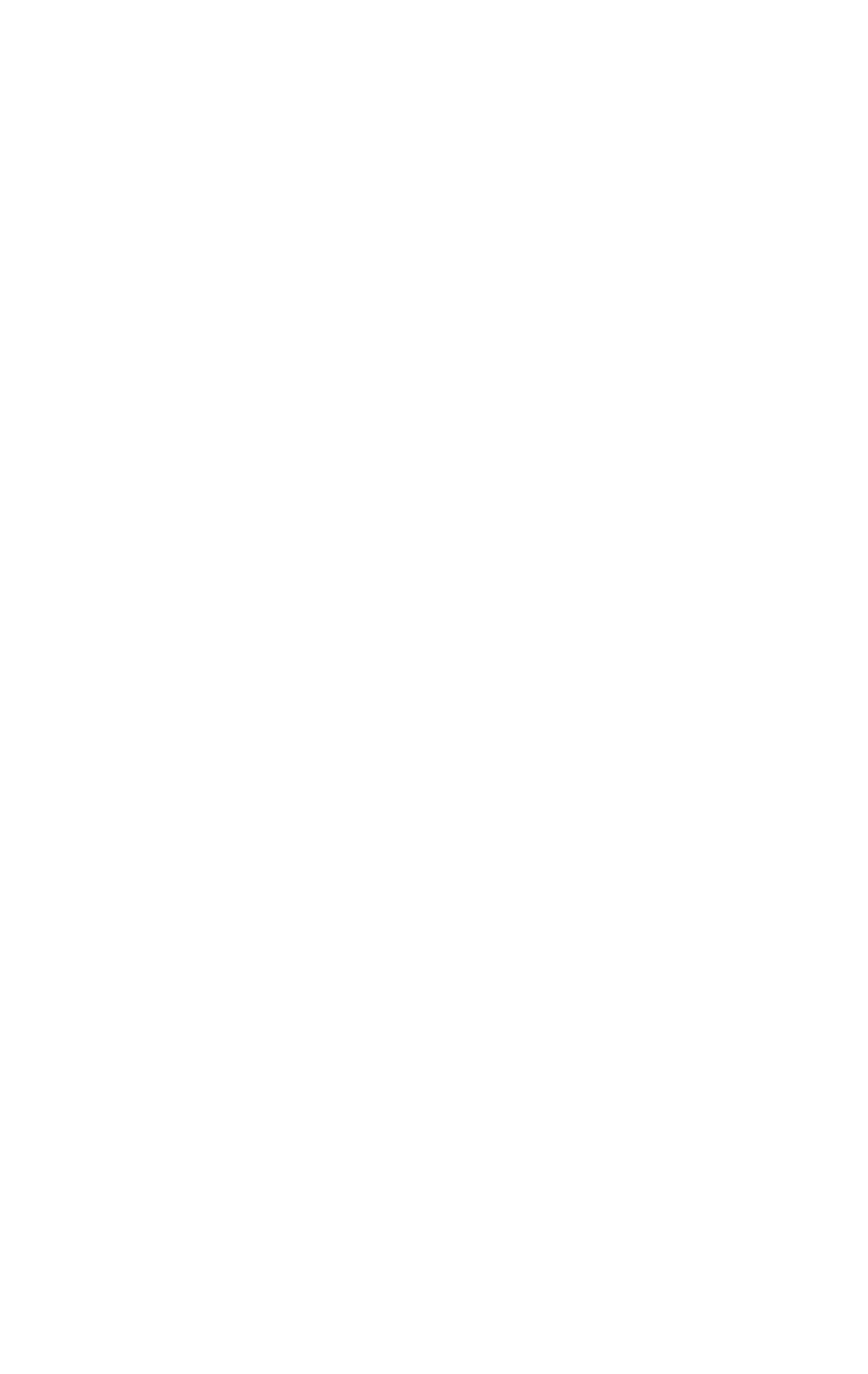

